\title{
DETEKSI PEMALSUAN COPY-MOVE DUPLICATED REGION PADA CITRA DIGITAL DENGAN KOMPUTASI NUMERIK
}

\author{
Endina Putri Purwandari \\ Program Studi Teknik Informatika, Fakultas Teknik, Universitas Bengkulu \\ Jl. WR. Supratman Kandang Limun, Bengkulu 38371 A INDONESIA \\ (telp: 0736-341022; fax: 0736-341022) \\ endinaputrip@gmail.com
}

Abstrak: Identifikasi keaslian dan integritas citra digital menjadi penting dalam forensik digital. Makalah ini mengusulkan metode pasif yang efektif untuk mendeteksi pemalsuan copy-move pada duplicated region. Implementasi metode ini dilakukan pertama-tama dengan citra input diproses dengan transformasi wavelet, lalu mengekstraksi fitur SVD pada blok citra yang telah mengalami perubahan geometri, dan beberapa gangguan. Selanjutnya melakukan pemeriksaan kesamaan karakteristik fitur antara bagian yang disalin dan ditempelkan, setiap fitur SVD menjadi query dalam pencocokan blok citra dengan tetangga terdekat. Ekperimen menunjukkan metode ini efisien dalam komputasi, robust, dan sensitif terhadap region citra berbeda yang telah mengalami beberapa perubahan pemprosesan citra.Kata Kunci: Copy-Move, Wilayah Terduplikasi, Pemalsuan Citra, Dekomposisi Nilai Singular, Pencocokan Blok.

Abstract: The identification of digital image authenticity and integrity is important in digital forensics. This paper proposes a passive method that effective to detect copy-move forgery with duplicated region. The method implementation of method, firstly input images are processed with wavelet transform, and then feature extraction was applied on them with SVD on block of changed geometry images and noise. Next, we check the feature similiarities between copied and pasted block, each SVD feature become a query in block matching with nearest neighbors. Experiment showed that this method is more robust, computational efficien, and sensitive to detect image forgery that undergone several changes in image processing.

Keyword: duplicated region, image forgery, singular value decomposition, matching block.

\section{PENDAhUluAN}

Pesatnya perkembangan teknologi digital menyebabkan dokumen digital mudah dimanipulasi termasuk dokumen citra digital. Saat ini, citra merupakan bagian yang penting dalam kehidupan manusia. Dengan ketersediaan paket software manipulasi yang berteknologi tinggi akan menyebabkan citra digital lebih mudah dimanipulasi bahkan oleh pengguna yang tidak professional. Kejahatan dalam pemalsuan citra digital menjadi masalah serius pada beragam bidang. Pengujian keaslian citra menjadi hal yang penting dan signifikan di semua wilayah sosial, terutama ketika citra digunakan sebagai referensi surat kabar, pembuktian kesimpulan dalam paper akademik, landasan pengambilan kebijakan peradilan, dan laporan perusahaan. Pemalsuan citra digital akan menyebabkan kerugian yang tidak dapat diperkirakan. Sebagai konsekuensi perlu meningkatkan perhatian lebih untuk memeriksa keaslian citra.

Manipulasi citra digital menjadi masalah serius untuk proteksi privasi individu seperti hak cipta dan publikasi karya. Citra digital yang telah dimanipulasi biasanya mengalami serangkaian operasi pemrosesan citra untuk menutupi jejak. Seperti kompresi JPEG, Gaussian blur, dan Gaussian noise. Metode pemalsuan citra digital yang umum ditemukan adalah copy move, dimana bagian citra disalin dan ditempelkan untuk menutupi objek atau menambahkan objek. Metode 
untuk menguji keaslian citra digital terbagi menjadi dua pendekatan yaitu aktif dan pasif. Pendekatan aktif [1][2] dilakukan dengan penyisipan tanda tangan dan tanda air pada citra digital. Namun pendekatan aktif dapat menurunkan kualitas citra serta tidak semua peralatan digital disertai dengan fasilitas ini. Pendekatan pasif [3-9] merupakan bentuk penelitian yang baru dalam wilayah keamanan multimedia digital yang berbeda dengan pendekatan aktif. Pada pendekatan pasif tidak membutuhkan informasi spesifik yang disisipkan untuk memeriksa suatu citra hasil manipulasi atau tidak. Pengujian dengan pendekatan pasif dapat langsung memeriksa citra itu sendiri, sehingga lebih praktis dan efektif.

Beberapa skema diusulkan dalam literatur [3-9] untuk mendeteksi pemalsuan duplicated region. Fridrich [3] mengusulkan metode dengan menganalisis koefisien DCT dari setiap blok dan mengusulkan metode fuzzy untuk mendeteksi duplicated region, namun kompleksitas komputasi metode ini terlalu besar untuk aplikasi praktis. Dalam [4] Popescu mengusulkan deteksi dengan metode color filter array. Sedangkan pada [5] Popescu menggunakan Principal Component Analysis (PCA) untuk mendapatkan citra fitur blok palsu dalam proses identifikasi blok yang sama dalam citra. Tingkat robustness atau kekuatan metode ini tidak terlalu baik dan perlu ditingkatkan. Luo [6][7] menggambarkan metode robust dan efisien untuk mendeteksi dan mengetahui posisi region yang palsu. Myna [8] menggambarkan metode berdasarkan wavelet dan pemetaan log-polar. Pada [9] Guohuo Li, mengusulkan metode deteksi duplicated region dengan menghitung nilai singular citra. Metodemetode tersebut menunjukkan performa yang baik dalam robustness.
Ketujuh metode tersebut menggunakan fitur spesial untuk mencocokkan dua buah blok region. Metode tersebut terbukti robust terhadap operasi post-processing. Namun teknik yang ada memiliki keterbatasan, ketika salinan wilayah dirotasi maka pencocokan blok akan gagal. Terlihat pada gambar 1.(b) blok duplikat dapat tidak terdeteksi karena kegagalan metode tradisional.

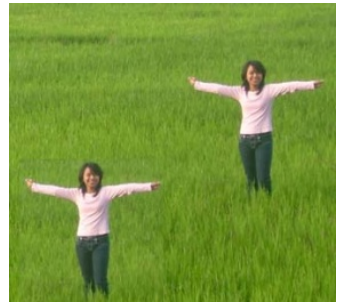

(a)

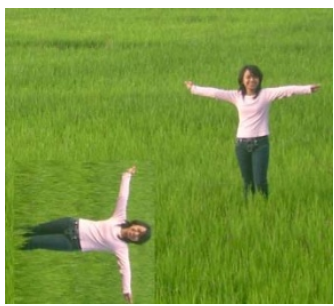

(b)
Gambar 1. Citra (a) wilayah terduplikasi (b) rotasi wilayah terduplikasi.

Untuk menangani duplicated region yang robust terhadap serangan citra, maka metode baru perlu diusulkan. Dalam laporan ini, penulis mengusulkan metode deteksi pemalsuan duplicated region dengan penggunaan semua fitur pada Singular Value Decomposition (SVD) yang robust terhadap serangan rotasi, translasi, pencerminan, blur, dan penskalaan. Artinya wilayah citra yang disalin akan dimanipulasi dengan operasi geometri dahulu sebelum ditempelkan. Algoritma yang diusulkan ini memiliki kompleksitas komputasi rendah dan lebih robust terhadap pemprosessan citra, seperti skala, rotasi, pencerminan, translasi, dan Gaussian blurring.

Untuk mereduksi biaya komputasi, penelitian ini mengajukan "Pendekatan Deteksi Duplicated Region Berdasarkan Singular Value Decomposition (SVD) dan Domain Wavelet Transformation (DWT)”. Proses awal, dimulai dengan reduksi dimensi citra dengan DWT dan selanjunya penggunaan SVD untuk mempercepat 
perhitungan nilai singular untuk semua blok citra hasil wavelet. Nilai vektor singular akan diurutkan secara lexicographic dan blok duplikasi dalam daftar terurut. Perbandingan blok tersebut dilakukan selama langkah pendeteksian. Hasil eksperimen menunjukkan pendekatan ini tidak hanya meningkatkan efisiensi, namun juga menentukan lokasi wilayah terduplikasi secara akurat bahkan untuk citra dengan kompresi tinggi.

\section{LANDASAN TEORI}

Pada paper ini, mengusulkan metode deteksi pemalsuan duplicated region yang robust terhadap serangan rotasi, translasi, pencerminan, blur, dan penskalaan. Dengan citra yang manipulasi geometris dan menyerang wilayah yang akan disalin sebelum ditempelkan. Metode-metode sebelumnya diatas belum dapat mendeteksi duplicated region yang diserang karena tidak melakukan sinkronisasi wilayah pada saat pencarian blok yang sama. Pada bagian ini mengenalkan korelasi antara wilayah citra yang disalin dan wilayah citra yang ditempelkan untuk memeriksa keaslian citra. Proses deteksi terdiri dari dua langkah utama : (1) ekstraksi fitur citra dan (2) pencocokan blok.

\section{A. Ekstraksi Fitur Citra}

Discrete Wavelet Transform (DWT): Discrete Wavelet Transform (DWT) merupakan teknik dekomposisi multilevel lokalisasi fitur dalam ruang dan frekuensi. Hasilnya dapat bermanfaat dalam beberapa aplikasi, seperti kompresi data, deteksi fitur citra dan penghilangan noise [9].

Setiap level DWT, citra didekomposisi menjadi empat sub bagian. Keempat sub bagian citra didapat dari aplikasi terpisah filter low-pass L dan filter high-pass $\mathrm{H}$, baik keduanya berkerja terhadap baris dan kolom citra. Dekomposisi wavelet tersebut membagi citra menjadi approsimaksi resolusi rendah (LL), komponen detail horizontal (HL), vertikal (LH) dan diagonal (HH). Keempat bagian dapat dikombinasikan kembali untuk mendapatkan citra sebelum didekomposisi. Gambar 2(a) menunjukkan dekomposisi pada level satu dan gambar 2(b) menunjukkan teori dekomposisi pada level dua.

\begin{tabular}{|c|c|c|c|c|}
\hline \multirow[b]{2}{*}{ LL1 } & \multirow[b]{2}{*}{ HL1 } & LL2 & $\mathrm{HL} 2$ & \multirow{2}{*}{ HL1 } \\
\hline & & IHP & $\mathrm{HH} 2$ & \\
\hline LH1 & HH1 & \multicolumn{2}{|c|}{ LH1 } & HH1 \\
\hline
\end{tabular}

(a) (b)

Gambar 2. Dekomposisi wavelet (a) level 1 dan (b) level 2

Ide dasar penggunaan DWT adalah untuk mereduksi ukuran citra di setiap level. Seperti citra persegi dengan ukuran $2^{j} \times 2^{j}$ piksel pada level $L$ adakan tereduksi menjadi ukuran $2^{j / 2} \times 2^{j / 2}$ pada level $L+1$. Dalam metode yang diusulkan, citra input didekomposisi dengan DWT untuk mendapatkan koefisien wavelet yang berhubungan dengan sub-band frekuensi spasial citra, disebut $I_{j}^{\theta}$, pada resolusi level $j$ sub-band dan orientasi $\theta \in\{L L, L H, H L, H H\}$. Banyak energi pada citra berada di sub-band frekuensi rendah $I_{j}^{L L}$. Operasi penggeseran window hanya diaplikasikan pada $I_{j}^{L L}$.

\section{B. Singular Value Decomposition (SVD)}

Fitur nilai singulir memiliki tiga sifat dasar, seperti stabilitas, properti skala, dan invarian rotasi dimana menunjukkan properti geometri dan aljabar pada citra. SVD digunakan untuk ekstraksi feature semua blok. Komponen sub band frekuensi rendah digunakan untuk mereduksi representasi dimensi. Penggunaan dekomposisi nilai singulir, metode yang diusulkan mencapai ekstraksi vektor fitur pada blok citra, mengurangi dimensi ruang fitur blok dan meningkatkan resistensi noise. Teori dasar SVD adalah: 
Bila A suatu matriks citra dengan $A \in R^{N \times M}$, dengan SVD diekspresikan dalam bentuk

$$
A=U \Lambda V^{T}
$$

Dimana $\in R^{N \times N}, V \in R^{M \times M}$, baik $U \operatorname{dan} V$ adalah matriks ortogonal. $\Lambda \in R^{N \times M}$ adalah matriks diagonal $N \times M$ dengan bentuk:

$$
\Lambda=\left[\begin{array}{cc}
\Sigma_{r} & 0 \\
0 & 0
\end{array}\right]
$$

Dimana $\Sigma_{r}$ adalah matrik diagonal persegi dimana $R^{r \times r}$, maka

$$
\Sigma_{r}=\operatorname{diag}\left(\sigma_{1}, \sigma_{2}, \cdots, \sigma_{r}\right) .
$$

Dengan $r$ adalah rank $A$ yang sesuai dengan jumlah nilai singulir non-negatif. Diagonal positif pada $\Sigma_{r}$ disebut nilai singulir $A$ dan disusun menurut urutan terkecil

$$
\sigma_{1} \geq \sigma_{2} \geq \cdots \geq \sigma_{r}>0
$$

Block similiarity matching

Setelah wilayah objek ditunjukkan sebagai SV berdimensi $r$ maka fitur vektor $u$ dan $\mathrm{v}$ dimana $u=\left(u_{1}, u_{2}, \cdots, u_{r}\right)^{T} \quad$ dan $v=\left(v_{1}, v_{2}, \cdots, v_{r}\right)^{T}$, Euclidean distance $D(u, v)$ digunakan sebagai pengukuran kesamaan antara vektor :

$$
D(u, v)=\left(\sum_{\mathrm{i}=1}^{\mathrm{r}}(u(i)-v(i))^{2}\right)^{\frac{1}{2}}
$$

Pengenalan blok fitur dengan melihat persamaan dan kesesuaian blok yang secara efisien dapat digunakan untuk identifikasi blok yang sama pada satu citra. Pencarian secara sederhana dilakukan dengan menghitung jarak antar blok dalam sebuah citra. Berdasarkan nilai singulir untuk setiap blok yang diperoleh dalam bagian 2.1. Selanjutnya tiga matriks S, V, dan D disusun dengan memasukkan ketiga vektor nilai singulir ke dalam matriks [11]. Setiap baris vektor nilai singulir pada matriks S, V, dan D berkaitan dengan baris dan kolom dari blok window.

Untuk meningkatkan efisiensi dalam menemukan blok tetangga, beberapa struktur hirarki telah diusulkan seperti penggunaan pengurutan matriks S secara lexicographic. Lexicographic adalah cara pengurutan data seperti pada kamus kata. Jika terdapat dua blok yang serupa pada citra, maka vektor SV akan terletak pada baris yang berdekatan dalam matriks S.

Deteksi dilakukan secara lexicographic dengan mengurutkan baris vektor SV dalam matriks A, sehingga pasangan blok yang terduplikasi akan terletak berurutan [9]. Sedangkan matriks V dan D mengikuti indeks pengurutan dari matriks A. Langkah ini akan membutuhkan waktu $m n \log _{2}(m n)$, misalkan untuk ukuran citra $256 \times 256$ maka akan membutuhkan langkah sebanyak $256^{2}$ dimana secara komputasi sangat mahal. Namun dalam metode penelitian ini, ukuran citra tersebut direduksi dengan DWT hingga level 2, sehingga untuk citra masukan yang berukuran $256 \times 256$ akan direduksi menjadi $64 \times 64$ yang dapat memperkecil biaya komputasi.

\section{METODOLOGI}

Tahap awal metode ini adalah dengan membagi citra ke dalam blok-blok. Lalu blok tersebut akan digeser per satu piksel baik kesamping atau kebawah, untuk perbandingan fitur antar blok dan identifikasi wilayah duplikasi.

Detail langkah kerja metode deteksi untuk mengidentifikasi wilayah pemalsuan yang diusulkan dalam paper ini adalah sebagai berikut:

1) Citra input merupakan citra warna, pemrosessan dapat dilakukan dengan memisahkan setiap saluran warna R, G dan B.

2) Dekomposisi wavelet mulai level 1 dan level 2 untuk setiap saluran warna R, G, B untuk mereduksi ukuran citra input. Proses DWT ini menggunakan Haar Wavelet.

3) Partisi citra menjadi blok-blok kecil yang overlap. Tentukan window berukuran $B \times B$ dan geser hingga keseluruhan citra dengan 
perpindahan per satu piksel mulai dari kiri atas hingga kanan bawah. Blok berukuran $B \times B$ ini diasumsikan lebih kecil daripada ukuran wilayah duplikasi yang akan dideteksi. Jumlah blok untuk citra berukuran $M \times N$ sehingga jumlahnya $(M-B+1)(N-B+1)$ blok.

4) Untuk setiap blok, aplikasikan SVD dengan menggunakan (1) dan ekstraksi vektor fitur nilai singular dari (2). Simpan hasil ekstraksi pada matriks $S, V$, dan $D$.

5) Selanjutnya urutkan secara lexicographic semua fitur vektor pada matriks $S$ dan simpan dalam matrik $A$ dengan jumlah baris $(M-B+$ 1) $(N-B+1)$ beserta nilai indeksnya. Matriks $V$ dan $D$ juga diurutkan berdasarkan indeks dari matriks A. Nilai indeks ini menunjukkan posisi blok pada citra.

6) Pencocokan blok dengan menentukan relasi antara dua blok dengan threshold $\rho$. Bila $D(u, v) \leq \rho$ maka perlu verifikasi lebih lanjut.

7) Untuk dua blok tersebut, asumsikan blok-1 dengan koordinat $(i, j)$ dan blok-2 dengan koordinat $(k, l)$ merupakan dugaan wilayah duplikasi dengan $C_{12} \geq S$

$C_{12}=\max \{a b s(i-k), a b s(j-l)\}$

Dimana $C_{12}$ adalah koordinat offset antara blok 1 dan blok 2. Nilai threshold $s$ adalah offset maksimum antara wilayah duplikat. Untuk meningkatkan kemampuan dengan eliminasi pseudomatching [11], rasio jarak terdekat dengan melihat tetangga terdekat kedua yang didefinisikan dengan:

$$
R=\frac{\min _{D}}{\operatorname{secmin}_{D}}
$$

Dimana $\min _{D}$ adalah tetangga terdekat pertama dan $\operatorname{secmin}_{D}$ adalah tetangga terdekat kedua. Keberadaaan wilayah terduplikasi dapat diterima bila $R \leq \omega$ dimana $\omega$ adalah threshold. Rasio $R$ mengeliminasi $90 \%$ dari kesalahan deteksi sehingga keakuratan pencocokan dapat ditingkatkan.

8) Identifikasi wilayah palsu. Pada sifat citra, tidak mungkin menemukan wilayah identik dan koheren, sehingga dapat digunakan sebagai bukti pemalsuan. Oleh karena itu, blok yang sesuai memenuhi threshold yang ditentukan akan ditandai dengan warna yang sama di setiap channel R, G, dan B sebagai dugaan wilayah terduplikasi.

9) Deteksi wilayah pemalsuan citra dari setiap channel R, G, dan B digabungkan kembali, untuk memperoleh keseluruhan citra warna hasil deteksi dengan wilayah penandaan blok sebagai bukti duplicated region.

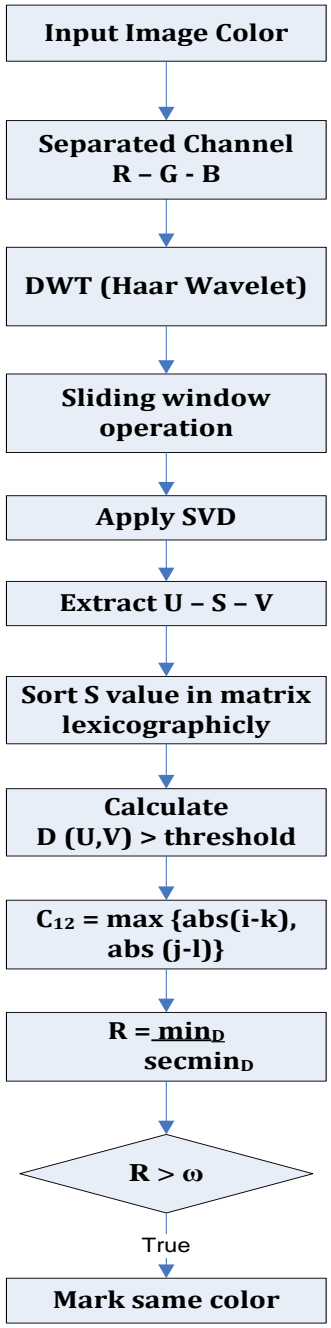

Gambar 3. langkah kerja metode deteksi copy-move (duplicated region) 


\section{HASIL DAN PEMBAHASAN}

Metode yang diusulkan telah diimplementasikan dengan MATLAB $^{\circledR}$ versi 7.8.0.347 (R2009a). Lingkungan eksperimen adalah notebook dengan prosessor $2.0 \mathrm{GHz}$ dan memori 1 GB. Pengujian ditunjukkan pada beragam citra dengan ukuran duplicate region berbeda dan manipulasi serangan geometris pemrosesan citra berbeda. Citra eksperimen diperoleh dengan mengunduh dari internet.

Dalam eksperimen ini, citra yang digunakan adalah citra warna dengan format *.tif. Pemrosesan citra input berwarna dapat diubah menjadi citra grayscale atau proses dilakukan secara independen untuk setiap channel warna RGB. Hasil yang diperoleh dari ketiga channel tersebut digabungkan kembali menjadi satu citra. Ukuran citra yang digunakan dalam pengujian adalah 256x256. Untuk mengevaluasi robustness and sensitivitas metode, penulis melakukan beberapa pemrosesan citra untuk citra palsu.

Eksperimen didesain untuk mendeteksi duplicated region dengan beragam sudut rotasi, skala, blur, translasi dan pencerminan. Salah satu masalah penting dalam metode deteksi duplicated region adalah kompleksitas komputasi karena mekanisme pencocokan blok. Beberapa artefak telah digunakan untuk mereduksi kompleksitas komputasi. Salah satunya mengunakan DWT untuk mencari sub-band ruang frekuensi rendah pada citra dan penggunaan SVD untuk mereduksi dimensi setiap blok dan mendapatkan fitur setiap blok. Performa waktu, rata-rata runtime metode diusulkan untuk satu channel warna 256x256 dengan ukuran blok $\mathrm{B}=2$, waktu deteksi sekitar 11 sampai 15 detik, lebih baik daripada metode [6] dan [7]. Faktor skala duplicated region yang digunakan mulai 0.9 hingga 1.4. Rotasi dengan perputaran wilayah duplikasi sebesar 90, 180 dan 270 derajat. Tingkat blur mulai 0.1 hingga 0.3 piksel.

Tabel 1. Waktu percobaan

\begin{tabular}{|c|c|c|c|c|}
\hline No & Percobaan & $\mathbf{R}$ & $\mathbf{G}$ & B \\
\hline 1 & Duplikasi & 11.881120 & 11.757072 & 11.902492 \\
\hline 2 & Pencerminan & 12.785465 & 12.219749 & 13.338002 \\
\hline 3 & Transpose & 12.746113 & 13.496596 & 13.960855 \\
\hline 4 & Rotasi 90 & 13.338836 & 12.885411 & 13.208565 \\
\hline 5 & Rotasi 180 & 13.995734 & 12.735792 & 12.978250 \\
\hline 6 & Rotasi 270 & 13.158434 & 13.410102 & 13.767910 \\
\hline 7 & Skala 1.1 & 14.271386 & 12.566681 & 13.611236 \\
\hline 8 & Skala 1.2 & 14.616764 & 14.150798 & 13.322924 \\
\hline 9 & Skala 1.3 & 13.853661 & 13.050026 & 14.211818 \\
\hline 10 & Skala 1.4 & 13.537368 & 13.709185 & 13.423386 \\
\hline 11 & Skala 0.9 & 13.983606 & 14.388122 & 13.824505 \\
\hline 12 & $\begin{array}{l}\text { Blur Semua } \\
1\end{array}$ & 13.234912 & 14.341523 & 14.491703 \\
\hline 13 & $\begin{array}{l}\text { Blur Semua } \\
5\end{array}$ & 13.418940 & 13.149891 & 14.207552 \\
\hline 14 & $\begin{array}{l}\text { Blok Blur } \\
0.1\end{array}$ & 15.001079 & 13.198411 & 13.515646 \\
\hline 15 & $\begin{array}{l}\text { Blok Blur } \\
0.2\end{array}$ & 13.553236 & 13.544980 & 13.217835 \\
\hline 16 & $\begin{array}{l}\text { Blok Blur } \\
0.3\end{array}$ & 13.597335 & 13.526663 & 13.118411 \\
\hline
\end{tabular}

Berdasarkan eksperimen, nilai threshold yang digunakan mulai dari 0.1 sampai 0.0001. Hasil deteksi menunjukkan bahwa nilai threshold yang besar dapat membuat meningkatkan kesalahan deteksi wilayah duplikasi, namun dengan nilai threshold yang rendah akan meningkatkan deteksi yang benar. Ketika nilai threshold mendekati 0.1 menyebabkan kesalahan deteksi meningkat secara dramatis. Dalam eksperimen ini hasil deteksi yang lebih dapat diterima dan akurat dengan nilai antara 0.003 dan 0.008 . Ukuran blok yang digeser selama proses matching berukuran 2x2.

Menurut eksperimen pada ukuran blok berbeda, didapatkan semakin kecil ukuran blok maka semakin baik wilayah yang berhasil dideteksi dan semakin cepat waktu yang dibutuhkan dalam deteksi. Namun, semakin besar 
ukuran blok, maka keakuratan wilayah semakin berkurang dan waktu deteksi semakin lambat. Tabel 1 mengevaluasi waktu percobaan deteksi duplicated region yang telah mengalami postprocessing image.

Penggunaan DWT2 dapat mempercepat waktu proses sekitar 0.6 sampai 1.1 detik, namun masih memiliki keterbatasan tidak semua serangan citra duplicated region dapat dideteksi. Hal ini disebabkan karena, DWT level 2 mereduksi ukuran citra menjadi lebih kecil, sehingga blok tidak dapat menangkap fiturnya. Untuk operasi skala pada duplicated region, nilai matching tertinggi pada nilai 0.9 dan 1.1. Deteksi duplikasi rotasi tertinggi adalah 270 derajat. Untuk deteksi duplicated region di keseluruhan citra Gaussian blur bagus untuk semua level, sedangkan untuk Gaussian blur pada blok duplikasi saja sangat baik untuk blur 0.1 hingga 0.3 .

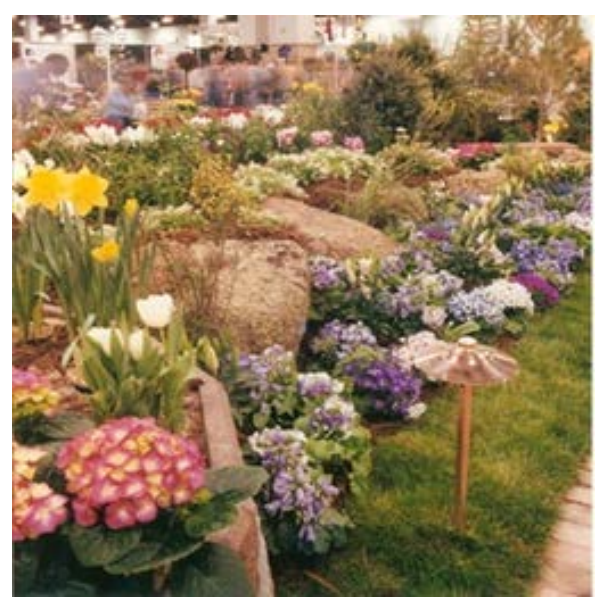

(a) Citra asli

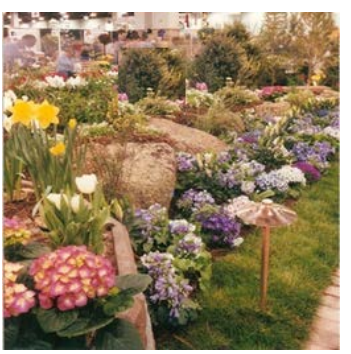

(b) Citra palsu duplicated region

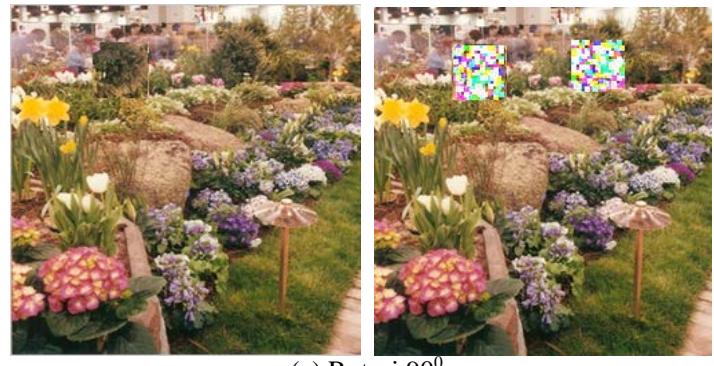

(c) Rotasi $90^{\circ}$

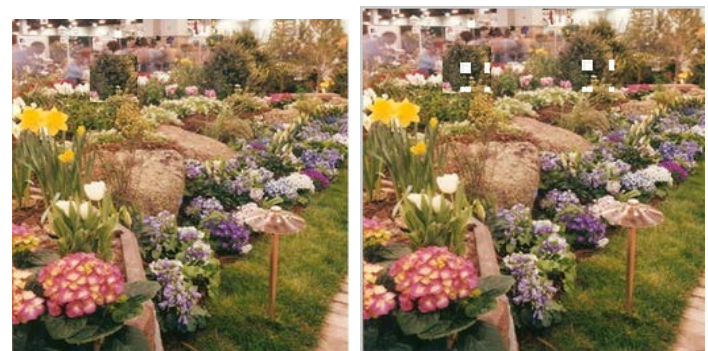

(d) Skala 0.9
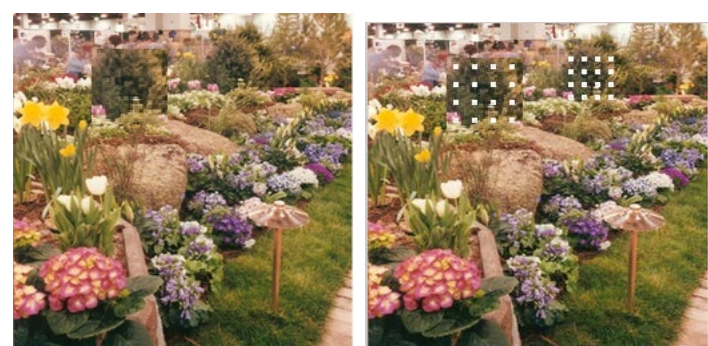

(e) Skala 1.4

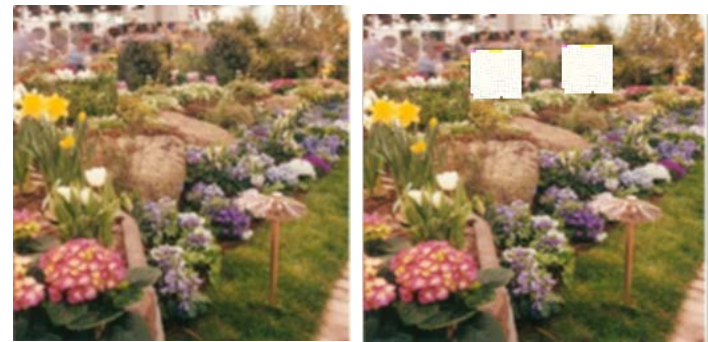

(f) Blur all 5
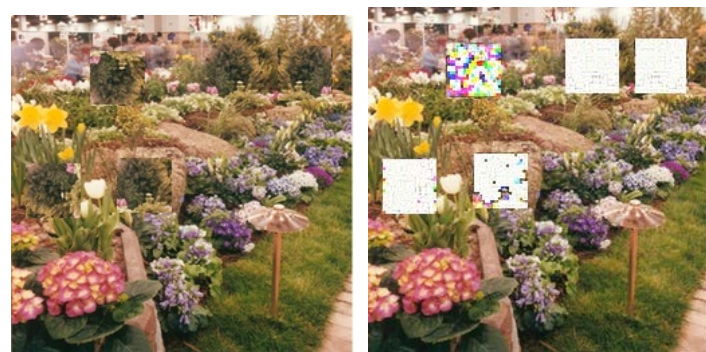

(g) Banyak blok terduplikasi dengan serangan translasi, pencerminan, dan rotasi.

Gambar 4. Hasil deteksi pemalsuan citra dengan beragam eksperimen 


\section{IV.KESIMPULAN DAN SARAN}

Dengan perkembangan teknologi pemalsuan citra, deteksi citra digital memiliki tempat dengan pemalsuan citra masih sulit deteksi bila bergantung pada satu alat forensik digital. Arah forensik citra digital diharapkan dapat menghasilkan alat multipleks forensik yang berhubungan dengan kebijakan dan hukum untuk pemalsuan digital.

Pemalsuan duplicated region adalah bentuk pemalsuan citra digital yang sering ditemukan. Dalam makalah ini penulis mengusulkan metode untuk mendeteksi pemalsuan copy-move pada duplicated region secara otomatis dan efektif menggunakan fitur SVD. Bila dibandingkan [4][5][6][7][8][9] algoritma dalam makalah ini memiliki kompleksitas komputasi yang rendah dan dapat mengatasi bermacam-macam operasi post processing pada blok citra seperti pencerminan, translasi, rotasi, penskalaan dan blur. Berdasarkan hasil analisis dan eksperimen membuktikan bahwa metode yang diusulkan memiliki kemampuan robustness yang baik untuk operasi tersebut. Sebagai penelitian lebih lanjut, perlu untuk meningkatkan kemampuan robustness deteksi pada citra kompresi JPEG dengan kualitas rendah.

\section{REFERENSI}

[1] Lin C. Y., and Chang S. F., "Semi-fragile watermarking for authenticating JPEG visual content", SPIE Security and Watermarking of Multimedia Contents II, 2000.

[2] Swaminathan A., Mao Y, and Wu M.,"Robust and secure image hashing”, IEEE Trans. on Information Forensics and Security, vol.1, no.2 2006, pp. 215-230.

[3] Fridrich J., Soukal D., and Lukáš J., "Detection of copy-move forgery in digital images”, Proceedings of Digital Forensic Research Workshop, Cleveland, 2003.

[4] Popescu A., and Farid H., "Exposing digital forgeries in color filter array interpolated images”, IEEE Trans. Signal Processing, vol. 53,no. 10, 2005, pp. 39483959.

[5] Popescu A., and Farid H., "Exposing digital forgeries by detecting duplicated image regions”, Dartmouth College, USA, TR2004-515, 2004.

[6] Luo W. Q., Huang J. W, and Qiu G. P., "Robust detection of region duplication forgery in digital image”, Journal of Computers, vol. 30, no. 11, 2007, pp. 1998-2007.

[7] Luo W. Q., Qu Z. H, Pan F., and Huang J. W., “A survey of passive technology for digital image forensics”, Front. Computer Science. China, vol.1, no.2 2007, pp.166-179.

[8] Myrna A.N., Venkateshmurthy M.G., "Detection of Region Duplication Forgery in Digital Images Using Wavelets and Log-Polar Mapping”, Conference on Computational Intelligence and Multimedia Applications, Dec. 2007, Vol.3, pp. 371-377

[9] Guohui Li, Qiong Wu, Dan Tu, and Shaojie Sun. “A Sorted Neighborhood Approach for Detecting Duplicated Region in Image Forgeries Based on DWT and SVD”. Multimedia and Expo, 2007, IEEE International Conference. 2-5 July 2007. Pp 17501753.

[10] Amara Graps. “An Introduction to Wavelets”. IEEE Computational Science and Engineering. 1992. Pp. 2(2):50-61

[11] Zhang Ting, Wang Rang-ding, “Copy Move Forgery Detection based on SVD in Digital Image”, IEEE International Conference, 2009.

[12] Gonzalez R.C., Woods R.E., "Digital Image Processing”. $3^{\text {rd }}$ Edition Reading. MA: AddisonWesley. 1992. 